Aim of the study: PTEN is an important gene whose protein product is double specific phosphatase holding key regulatory functions in sending signals from membrane receptors for growth factors into the cell downstreams. Its participation, mainly by PI3K/AKT signaling pathway in the pathomechanism of many malignant cancers was unambiguously confirmed.

The PTEN function gets disturbed on many levels and for various reasons. Disorders of PTEN protein expression seem to be even more common in many carcinomas.

The aim of the study is to enquire the meaning of PTEN expression in the cancer transformation process in large intestine glandular polyps.

Material and methods: The group includes 40 patients, 21 men and 19 women, age median 64 years (51-83) qualified to endoscopic removal of large intestine polyp. Tissue material obtained during polyp removal endoscopy was immediately fixed in $4 \%$ buffered formalin solution with the mixture of phosphatase activity inhibitors (PhosStop Roche). Time of fixation 24-48 h. After fixation, the material was embedded in paraffin. PTEN visualization was based on specific rabbit monoclonal antibodies (Cell Signaling). The expression of PTEN protein in large intestine and rectum polyps was marked by a semiquantitative method and an attempt to correlate the results with the acknowledged clinical and histopathological malignancy risk factors was undertaken. Results: Loss or weakening of protein expression was found in $45 \%$ cases. Moreover, the relationship between polyp diameter and a loss of PTEN expression was proved. The received results can indicate a significant participation of PTEN gene in early oncogenesis stages of large intestine cancer.

Key words: PTEN, colorectal polyp, colorectal cancer, familial adenomatous polyposis.

\section{Analysis of PTEN expression in large intestine polyps and its relation to the recognized histopathological and clinical risk factors for cancer development in this location}

Dariusz Waniczek ${ }^{1}$, Mirosław Śnietura ${ }^{2}$, Wojciech Pigłowski², Jerzy Rdes ${ }^{3}$, Agnieszka Kopeć́ ${ }^{2}$, Joanna Młynarczyk-Liszka², Marek Rudzki', Krystyna Hudyka ${ }^{1}$, Jerzy Arendt ${ }^{1}$, Dariusz Lange ${ }^{2}$

${ }^{1}$ Chair and Department of General and Gastrointestinal Surgery, Bytom

Medical University of Silesia, Katowice, Poland

2Pathology Department, Maria Skłodowska-Curie Memorial Cancer Center and Institute of Oncology, Gliwice Branch, Poland

3Department of Health Economics, Medical University of Silesia, Katowice, Poland

\section{Introduction}

Large intestine cancer is a serious problem of public health due to its frequency and the resulting high mortality rate. One of the successes of contemporary medicine is preventive large intestine examinations, where its precancerous states, i.e. glandular polyps, are removed. This effective preventive activity is based on a concept of multistage cancer transformation in the polypcancer sequence worked out by E.R. Fearon and B. Vogelstein in 1990 [1]. It is still valid with many supplements for the development of most large intestine cancers: sporadic and family determined.

Cancer transformation is a very complex and multistage process. More and more data show that it is a result of various genetic and epigenetic changes whose products are significant for cell metabolic balance in each stage of its development cycle.

Phosphorylation of the proteins taking part in regulating transformations of the cell cycle is one of the most important processes [2].

PTEN protein is a phosphatase with double function. One of them is to disconnect phosphate residues from cell phosphoproteins. Another is to inhibit the tyrosine kinase B pathway (PI3K/AKt), through catalysis of the 3-phosphorane group detachment reaction from phosphatidylinositol -3,4,5-trisphosphate [3].

It seems that the PTEN gene (Phosphatase and Tensin Homolog Deleted on Chromosome TEN) belongs to suppressor genes mainly because of the control over the PI3K/Akt signaling pathway. It is located on chromosome 10q23. The structure of the PTEN gene is complicated. It consists of 9 exons coding a protein of molecular mass $47 \mathrm{kDa}$ built of 403 amino acids [4].

A molecule of PTEN protein consists of two main domains: the catalytic domain of phosphatase activity and the C2 domain binding it to the cell membrane. Germinal and somatic mutations of the PTEN gene block and interfere with the cell signaling pathway, which leads to maintaining cell divisions and apoptosis blockade. Apart from the influence on proliferation processes and apoptosis, it also regulates angiogenesis processes, having anti-angiogenesis properties [5].

Mutations and deletions of the PTEN gene are often found in various malignant human cancers. It seems that disorders of normal expression of the PTEN protein itself in many cancers are even more common [5-9]. 


\section{Aim of the study}

The aim of the study is to investigate the significance of PTEN protein expression in the cancer transformation process of large intestine adenomatous polyps.

\section{Material and methods}

The study included a group of 40 patients with diagnosed large intestine polyps (32 cases) and rectal polyps (8 cases) treated by endoscopy or by surgery. Clinical and histopathological characteristics of the group are presented in Table 1. In detail: the majority of the polyps originated from the large intestine and were low grade tubular adenomas with sessile shape. The diameter of the polyps was equally distributed between two groups: small, i.e. less than $7 \mathrm{~mm}$, and big, i.e. more than or equal to $7 \mathrm{~mm}$. Because of incomplete pathological reports it was impossible to determine the shape of polyps in 5 patients and dysplasia grade also in 5 patients. The cases were excluded from analyses comprising these factors.

Study material included polyp tissue fixed for 24-48 hours in buffered $4 \%$ formalin with a mixture of phosphatase activity inhibitors (PhosStop Roche). Tissue material taken during endoscopic polyp removal was immersed in paraffin, cut in series and examined histopathologically and by additional methods. PTEN protein expression was detected in histopathological slices of $5 \mu \mathrm{m}$ thickness with anti-PTEN monoclonal antibody of 138G6 clone (cell signaling technology) dissolved $1: 75$. This antibody shows specificity in relation to the total endogenic cell pool of PTEN protein with no regard to the state of its phosphorylation and is obtained as a result of rabbit immunization by a synthetic peptide corresponding to the 100 terminal amino acid sequence forming the carboxyl end of this protein. That is why only normally built PTEN protein of full length is detected, while all the mutations of sense change and nonsense ones, leading to its shortening, lead to immunoreactivity loss.

Table 1. Clinical and histopathological characteristics of the study group

\begin{tabular}{|ll}
\hline Feature & Values \\
\hline age median & 64 years (51-83) \\
\hline gender & male: 21 \\
& female: 19 \\
\hline location & large intestine: 32 \\
& rectum: 8 \\
shape & pedunculated: 15 \\
& semi-sessile: 1 \\
& sessile: 19 \\
& lack of data: 5 \\
& small (less than 7 mm): 17 \\
& big ( $\geq 7$ mm): 23 \\
diameter & adenoma tubulare: 36 \\
& adenoma tubulo-villosum: 3 \\
& adenocarcinoma: 1 \\
histological type & low grade: 24 \\
& medium grade: 10 \\
& high grade: 1 \\
lack of data: 5 \\
\hline
\end{tabular}

Epitope retrieval took place in TE alkaline buffer of $\mathrm{pH} 9.0$ (Dako Denmark). However, visualization of the antigenantibody complex was done by the system EnVisionHRP/DAB+ (Dako, Denmark): 30 minutes after incubation of slices with secondary anti-rabbit antibody marked with horseradish peroxidase, a substrate for the enzyme in the DAB form was added. For each case a negative control was made by replacing the primary antibody with water, and for the whole group a positive control was made, applying cell blocks from the cell culture lines of the known PTEN gene sta-
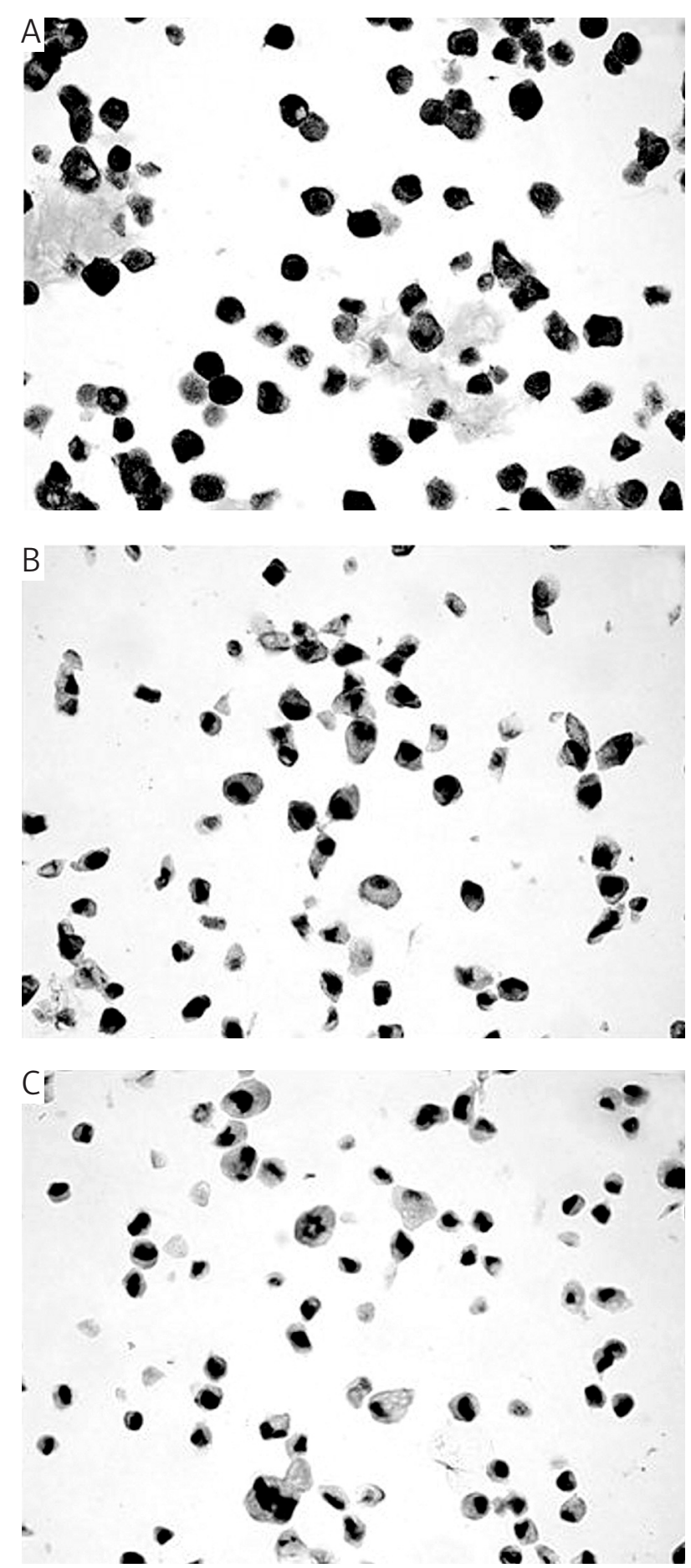

Fig. 1. PTEN expression in control group examined with antibody 6H2.1: A - MCF-7, B - NIH-1299, C - PC-3 
A431

HaCat

MCF-7
NIH-1299

PC-3

V2-OS
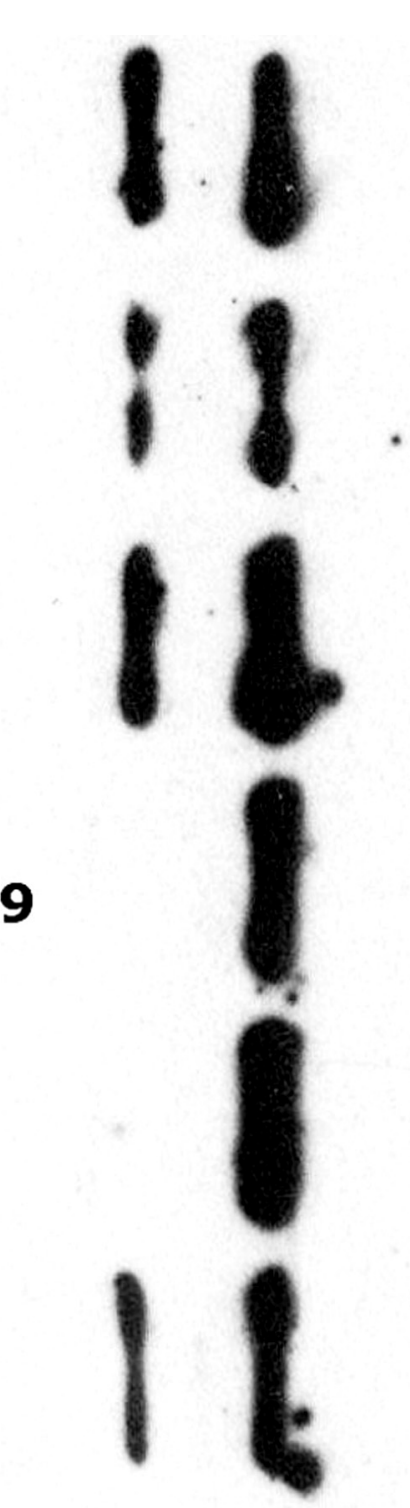

Fig. 2. Antibody $6 \mathrm{H} 2.1$ specificity in cell lysates of the line A431, HaCat, MCF-7, NIH-1299, PC-3, U2-OS in Western blotting test

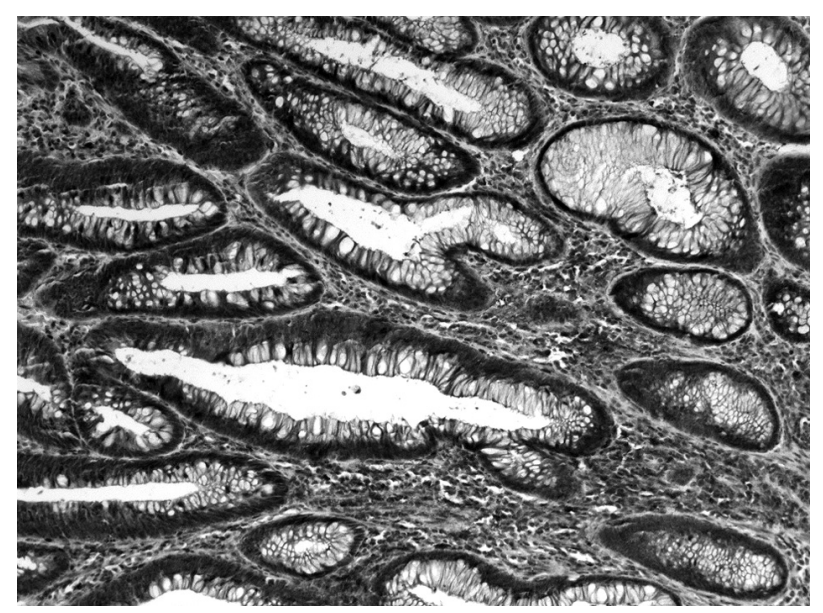

Fig. 3. Preserved PTEN protein expression in interstitium cells and intestinal epithelium of adenoma tubulare. Anti-PTEN immunohistochemical staining, original magnification 10x tus (MCF-7, NIG-1299, PC3, HaCat, U2-OS) (Fig. 1). Additionally, the antibody specificity was confirmed by Western blotting method of the selected cell line lysates of the known PTEN gene status (Fig. 2). Immunohistochemical reaction was evaluated in the Olympus BX41 light microscope with the total magnification 100x and 200x on a three-grade scale considering staining intensity within cell cytoplasm of polyp epithelium in the foci of the smallest intensity:

- 0 - no reaction in polyp epithelium,

- 1 - staining reaction in epithelium weaker than in the environment,

- 2 - staining reaction of the same intensity in polyp epithelium and in the environment.

Additionally, intensity of immunostaining within the cellular component of the polyp interstitium and its immediate environment served as an internal control, according to the method given by Perren et al. [10]. Representative images of the polyp pattern of normal PTEN expression are presented in photograph 3, while focal loss and expression weakening are presented in Fig. 4.

Statistical analysis was performed using Statistica 8.0 (StatSoft) using single-factor analysis of variance (ANOVA) and Spearman's non-parametric correlation test.

\section{Results}

Diagnostic results were obtained for all the examined cases. Among 40 polyps, normal PTEN protein expression was observed in 22 cases, which is $55 \%$, decreased expression in 16 (40\%), but no expression in 2 cases (5\%); in one of them a focus of adenocarcinoma was found. A summary of the PTEN expression profiles in polyps is presented in Table 2.

In the course of further analysis a relationship between PTEN protein expression intensity and polyp diameter was found. No relationship was found between PTEN expression and other clinical and histopathological features such as age, gender, shape, localization, dysplasia grade or histopathological type.

Average polyp diameter in the group without PTEN protein expression was $25 \mathrm{~mm}$, while polyps showing decreased expression of this protein had a mean diameter of $11.1 \mathrm{~mm}$. The polyps of normal PTEN expression were the smallest; their diameter was $6.2 \mathrm{~mm}$. A comparison of those relations is presented in Table 3.

In single-factor analysis of variance (ANOVA) of polyp diameter in subgroups created with reference to PTEN protein expression, only highly significant differences $(p=0.00005)$ were observed. The results of the analysis are summarized in Table 4, and a graphic interpretation is presented in Fig. 2.

Furthermore, the non-parametric Spearman's test confirmed a moderately strongly expressed $(R=0.55)$ negative correlation between polyp diameter and PTEN protein expression. A summary of the analysis is presented in Table 5, and graphic interpretation in Fig. 1.

\section{Discussion}

The PTEN gene is a suppressor gene of cancer transformation which is responsible for the whole range of clinical symptoms. In Cowden disease inherited in an autosomal manner, multiple hamartomatous tumors of ectodermal, meso- 
dermal and endodermal origin are dominant. Polyps of the alimentary duct occurring in about $35 \%$ of patients have various histopathological forms, most often polyps of hamartoma type. An admixture of glandular cells occurs sometimes in those polyps; however, cancer transformation, though very frequent, is not dominant in those conditions [11]. Discovery of the PTEN gene's role in several hereditary diseases of higher probability of cancer disease has led to studies on the potential role of this gene in the development of sporadic neoplastic tumors. It seems that inactivation or disturbance of this protein's function is related to the oncogenesis of many human cancers. It was found in breast, thyroid, lung, prostate, endometrium, primary liver and large intestine cancer [5-12]. The loss of PTEN protein functionality is one of the most often reported pathologies among human malignant tumors. PTEN has the second, after the P53 gene, highest frequency of the observed mutations. It is estimated that the mutations of at least one allele of the PTEN gene occur in $50-80 \%$ of cases of sporadic endometrial cancers, cerebral gliomas and prostate cancers and in $30-50 \%$ of breast, large intestine and lung cancers [12]. According to Leslie et al. [9] the loss of PTEN protein expression was found in large intestine cancers in $17 \%$ of patients, including the loss of gene heterozygosity in 22\% of cancers and PTEN gene mutations in $11 \%$ of cancers.

At this level of knowledge, the concept of polyp-cancer transformation from a small dysplastic focus in epithelium, through gradual increase of the change into adenoma, which through further grades of dysplasia shows the features of invasive cancer, will not clarify in an individual patient which polyp out of many different advancement stages will undergo progression into invasive cancer. We only know that the polyps that most often undergo malignant changes have a histological structure with predominance of villous elements, are massive, have a diameter more than $2 \mathrm{~cm}$ and have a high dysplasia level. The transition of adenoma into cancer occurs through a series of mutations in the genes most important for the development of cancer, and if this process starts, it will last on average 10 years. However, there are no reli-

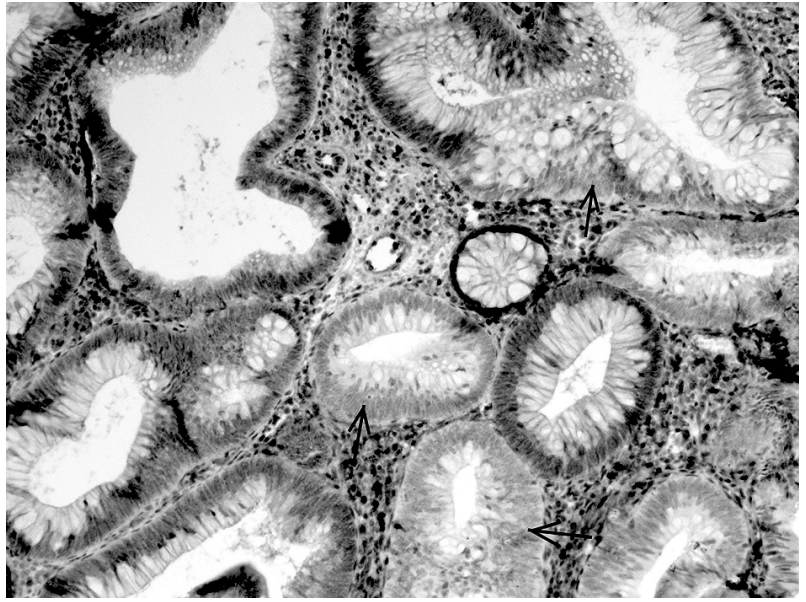

Fig. 4. Focal decrease and loss of PTEN protein (see arrows) in glandular polyp. Anti-PTEN immunohistochemical staining, original magnification $10 \times$

able research methods for selecting a group of those polyps (or patients) in which the risk of cancer growth in polyps is the highest. It is known that at the early stage of adenoma transition into cancer, a mutation leading to activation of K-RAS protooncogene is created. The importance of other oncogenes such as C-myc and disorders of APC, MCC, P 53 suppressor genes, and also of mutator genes was shown. It is also accompanied by epigenetic changes and microsatellite instability.

In processes of protein phosphorization the crucial role is played by cell cycle kinases, including B tyrosine kinase (Akt). PI3K phosphatidylinositol kinase signaling protein, whose PTEN protein is an inhibitor, is related to it [3].

With the cooperation of PTEN, the PI3/Akt axis is a known and strong regulator of cell survival. It has a multilevel antiapoptotic action, both as a result of transcription inhibition of caspase-9 gene and BAD protein and its phosphorylation and blocking of the mitochondrial mechanism of programmed cell death. It also increases cell proliferation, mak-

Table 2. PTEN expression in relation to polyp diameter

\begin{tabular}{|c|c|c|c|c|}
\hline & PTEN expression & $\begin{array}{c}\text { Polyp diameter } \\
\geq 7 \mathrm{~mm}\end{array}$ & $\begin{array}{c}\text { Polyp diameter } \\
<7 \mathrm{~mm}\end{array}$ & Line total \\
\hline $\begin{array}{l}\text { count } \\
\text { percentage in column* } \\
\text { percentage in category**}\end{array}$ & negative & $\begin{array}{c}2 \\
8.70 \% \\
100.00 \% \\
5.00 \%\end{array}$ & $\begin{array}{c}0 \\
0.00 \% \\
0.00 \% \\
0.00 \%\end{array}$ & $\begin{array}{c}2 \\
5.00 \%\end{array}$ \\
\hline $\begin{array}{l}\text { count } \\
\text { percentage in column } \\
\text { percentage in category } \\
\text { percentage of all cases }\end{array}$ & decreased & $\begin{array}{c}13 \\
56.52 \% \\
81.25 \% \\
32.50 \%\end{array}$ & $\begin{array}{l}\quad 3 \\
17.65 \% \\
18.75 \% \\
7.50 \%\end{array}$ & $\begin{array}{c}16 \\
40.00 \%\end{array}$ \\
\hline $\begin{array}{l}\text { count } \\
\text { percentage in column } \\
\text { percentage in category } \\
\text { percentage of all cases }\end{array}$ & normal & $\begin{array}{c}8 \\
34.78 \% \\
36.36 \% \\
20.00 \%\end{array}$ & $\begin{array}{c}14 \\
82.35 \% \\
63.64 \% \\
35.00 \%\end{array}$ & $55.00 \%$ \\
\hline $\begin{array}{l}\text { total } \\
\text { percentage total }\end{array}$ & total & $\begin{array}{c}23 \\
57.50 \%\end{array}$ & $\begin{array}{c}17 \\
42.50 \%\end{array}$ & 40 \\
\hline
\end{tabular}

* Percentage of cases within a group defined by a given polyp diameter

** Percentage of cases within a category defined by a certain PTEN expression 
Table 3. Distribution of polyp diameter in groups in relation to PTEN protein expression

\begin{tabular}{|lcccc|}
\hline PTEN & N & $\begin{array}{c}\text { Diameter } \\
\text { mean }\end{array}$ & $\begin{array}{c}\text { Diameter } \\
\text { SD }\end{array}$ & Diameter SE \\
\hline negative & 2 & 25.00 & 7.07 & 5.00 \\
\hline decreased & 16 & 11.13 & 7.79 & 1.95 \\
\hline normal & 22 & 6.18 & 2.17 & 0.46 \\
\hline total & 40 & 9.10 & 6.83 & 1.08 \\
\hline
\end{tabular}

Table 4. Results of single factor variance analysis (ANOVA) of polyp diameter variable in groups in relation to PTEN expression

\begin{tabular}{|ccccccc}
\hline SS & $\begin{array}{c}\text { Freedom } \\
\text { grades }\end{array}$ & MS & F & $p$ & $\begin{array}{c}\text { Test power } \\
(\boldsymbol{\alpha}=0.05)\end{array}$ \\
\hline PTEN & 758.577 & 2 & 379.289 & 13.227 & 0.000046 & 0.996 \\
\hline
\end{tabular}

Table 5. Analysis of PTEN expression correlation and polyp diameter by Spearman's test

\begin{tabular}{|lcccc|} 
& $\begin{array}{c}\text { Number } \\
\text { of cases }\end{array}$ & Spearman R & $t(\mathrm{~N}-2)$ & $\begin{array}{c}\text { Test } \\
\text { significance } \\
\text { level }\end{array}$ \\
\hline $\begin{array}{l}\text { Polyp \& PTEN } \\
\text { diameter }\end{array}$ & 40 & -0.544525 & -4.00203 & 0.000281 \\
\hline
\end{tabular}

ing the transition of G1/s phase through cyclin D1 and suppression of P27, an inhibitor of cyclin dependant kinases, easier. It was also shown that the mTOR pathway is an immediate PI3/Akt effector responsible for the increase of protein translation and synthesis. The spatial structure of the PTEN protein catalytic domain has critical significance for maintaining the protein phosphate activity. The catalytic center responsible for the reaction of phosphate residues splitting off the substrate is geometrically wider than in other phosphatases; therefore PTEN shows the activity of both tyrosine and serine/threonine phosphatase, and also dual specific phospholipid/phosphoprotein phosphatase [13].

Another postulated mechanism of cell suppression by PTEN is its influence on mitogen activated protein kinase and the kinase related to cell adhesion foci FAK (focal adhesion kinase). It was shown that PTEN, due to its phosphoprotein phosphatase activity, is able to deactivate both FAK directly and Ras indirectly, which are the common elements of the integrin signaling pathway and growth factors. An ability to modulate cell motility and migration [14] is an effect of this regulation.

Some studies also suggest that a part of PTEN suppressor activity results from activity of the $\mathrm{C} 2$ domain irrespective of kinases. However, it is the C2 domain which has crucial importance in intracellular protein location. It shows great affinity to membrane acid lipids, causing the displacement and gathering of PTEN in the vicinity of the cellular membrane, where its substrates are located [5, 15-17].

Simultaneously, in some cases of sporadic malignant cancers, a loss of PTEN protein expression was shown regardless of the lack of mutation within its gene. This may be proof of another, epigenetic pathomechanism of dysfunction $[18,19]$
The key role of kinases in the regulation of the cell cycle puts their activity under strict control and, as a result, complex control. Any mistakes in kinase control can select cell clones being eager to escape from the apoptosis pathway in the direction of proliferation. It seems that PTEN protein, mainly through Kinase Akt being a PI3K antagonist, plays an important role of protein suppressing polyp growth. It can be of changeable intensification depending on mutations appearing in it, which are responsible for tumor initiation and progression.

Cancer progression occurs in a continuous manner, while the process of acquiring consecutive genetic changes usually lasts many years. It seems that genetic changes occur in a certain preferred sequence, but it is not a rule.

There are still many unrecognized pathways leading to formation of a cancer in the large intestine. Only about 10\% of large intestine cancers have mutations in three "classical" genes of the Fearon-Vogelstein model: APC, K-RAS and P53 [20].

To understand better the influence of PTEN on cancerogenesis of large intestine and rectum cancer, we applied a research method where we evaluated its activity in polyps in different stages of development. The loss of PTEN expression found by us in benign precancerous states indicates the significant role of this gene in the pathomechanism of large intestine cancer already in the early stage of oncogenesis. Furthermore, the intensification of this process together with the increase of polyp physical dimensions recognized as a significant predictor of cancer transformation can suggest that PTEN dysfunction is one of the accumulating factors initiating multistage neoplastic process. Taking into consideration the latest concepts of obligatory PTEN haploinsufficiency put forward by Pandoli et al., according to which the loss of $20 \%$ of activity of this protein leads to a noticeable increase of cancer development risk, a possibility to evaluate tiny changes in PTEN activity (expression) is of crucial importance. A method of relative evaluation of expression suggested by Perren [10] used in this study and also applied successfully in many further studies has given the possibility to find out the loss or decrease of PTEN protein expression in $45 \%$ of observed polyps. How much this fact is related to the increase of personal risk of malignant cancer development is still an open question.

Fearon and Vogelstein's theory has been confirmed by clinical observations, morphological data and the results of molecular biology. However, only a small number of adenomas transform into malignant cancers. The decisions about polyps of size 5-9 mm or smaller are of special clinical importance; they are always doubtful and controversial [21]. The risk of detecting cancer foci in them is smaller than $1 \%$. The risk increases by $10 \%$ in cases of polyps of $1-2 \mathrm{~cm}$ diameter and by $45 \%$ in polyps of diameter bigger than $2 \mathrm{~cm}$ [22, 23]. Ambiguous opinions about the sizes of polyps to be removed, especially in the view of new screening possibilities such as computed tomography colography, make us pay attention to the cancer transformation process in large intestine polyps [21, 24].

Macroscopic polyp evaluation is not able to assess its character, and the results of the samples taken are not final. Although the risk of cancer development in a polyp is relat- 
ed to its histopathological structure, shape, size and number, we are not able to define for sure whether the removed polyp would turn into a malignant cancer within 5-10 years. So when the adenoma is discovered, a question arises if there has been or will be a transformation into a malignant cancer, should it be removed? Besides, polyps (adenomas) can reoccur even in $50 \%$ of patients after being removed, and a cancer can occur in $5 \%$ of patients after adenoma incision, which is why there arises another important question of whether and how these patients should be included in a control examination program [24, 25].

\section{Summary and conclusions}

As a result of rapid progress in molecular biology happening now, more and more genetic disorders are being discovered in patients with large intestine cancers. Neoplasm development occurs by alternative pathways; their precise recognition at the molecular level will make the study on searching for prognostic and predictive markers easier.

Fearon and Vogelstein's model was constructed owing to histopathological and clinical observations grounded on molecular biology discoveries showing that most malignant tumors in the large intestine are formed from earlier existing adenomas which increase their size and invasiveness gradually.

PTEN protein, and precisely, its lack or dysfunction, seems to participate in early stages of carcinogenesis in the large intestine; therefore the studies on its significance in this process should be continued.

Clinical data gathered in the last decades show that routine screening examinations can detect the disease in early stages of development, and through polypectomy, they decrease the frequency of its occurrence by stopping disease development in its early stages.

Predicators do not give the full characterization of cancer biology. Therefore, it seems important to study and search other, new prognostic and predictive factors.

\section{References}

1. Fearon ER, Vogelstein B. A genetic model for colorectal tumorigenesis. Cell 1990; 61: 759-67.

2. Parsons DW, Wang TL, Samuels Y, et al. Colorectal cancer: mutations in a signalling pathway Nature 2005; 436: 792.

3. Carnero A, Blanco-Aparicio C, Renner O, Link W, Leal JF. The PTEN/ $\mathrm{PI} 3 \mathrm{~K} / \mathrm{AKT}$ signalling pathway in cancer, therapeutic implications. Curr Cancer Drug Targets 2008; 8: 187-98.

4. Ali IU, Schriml LM, Dean M. Mutational spektra of PTEN/MMAC1 gene: a tumor suppressor with lipid phosphatase activity. J Natl Cancer Inst 1999; 91: 1922-32.

5. Tian T, Nan KJ, Wang SH, Liang X, Lu ChX, Guo H, Wang WJ, Ruan ZP. PTEN regulates angiogenesis and VEGF expression through phos phatase-dependent and -independent mechanisms in HepG2 cells. Carcinogenesis 2010; 31: 1211-9.

6. Li J, Yen C, Liaw D, et al. PTEN, a putative protein tyrosine phosphatase gene mutated in human brain, breast, and prostate cancer. Science 1997; 275: 1943-7.

7. Steck PA, Pershouse MA, Jasser SA, et al. Identification of a candidate tumour suppressor gene, MMAC1, at chromosome 10q23.3 that is mutated in multiple advanced cancers. Nat Genet 1997; 15: 356-62.

8. Simpkins SB, Peiffer-Schneider S, Mutch DG, et al. PTEN mutations in endometrial cancers with $10 \mathrm{q} \mathrm{LOH}$ : additional evidence for the involvement of multiple tumor suppressors. Gynecol Oncol 1998; 71: 391-5.

9. Leslie NR, Downes CP. PTEN function: how normal cells control it and tumour cells lose it. Biochem J 2004; 382: 1-11.

10. Perren A, Weng LP, Boag AH, et al. Immunohistochemical evidence of loss of PTEN expression in primary ductal adenocarcinomas of the breast. Am J Pathol 1999; 155: 1253-60.

11. Haggitt RC, Reid BJ. Hereditary gastrointestinal polyposis syndromes. Am J Surg Patrol 1986; 10: 871-87.

12. Salmena L, Carracedo A, Pandolfi PP. Tenets of PTEN tumor suppression. Cell 2008; 133: 403-14.

13. Chu EC, Tarnawski AS. PTEN regulatory functions in tumor suppression and cell biology. Med Sci Monit 2004; 10: 235-41.

14. Hlobilková A, Knillová J, Bártek J, et al. The mechanism of action of the tumour suppressor gene PTEN. Biomed Pap Med Fac Univ Palacky Olomouc Czech Repub 2003; 147: 19-25.

15. Raftopoulou M, Etienne-Manneville S, Self A, Nicholls S, Hall A. Regulation of cell migration by the C2 domain of the tumor suppressor PTEN. Science 2004; 303: 1179-81.

16. Yin Y, Shen WH. PTEN: a new guardian of the genome. Oncogene 2008; 27: 5443-53.

17. Chang CJ, Mulholland DJ, Valamehr B, Mosessian S, Sellers WR. Wu H: PTEN nuclear localization is regulated by oxidative stress and mediates p53-dependent tumor suppression. Mol Cell Biol 2008; 28: 3281-9.

18. Shi W, Zhang X, Pintilie M, et al. Dysregulated PTEN-PKB and negative receptor status in human breast cancer. Int J Cancer 2003; 104 : 195-203.

19. Goel A, Arnold CN, Niedzwiecki D, et al. Frequent inactivation of PTEN by promoter hypermethylation in microsatellite instability-high sporadic colorectal cancers. Cancer Res 2004; 64: 3014-21.

20. Samowitz WS, Slattery ML, Sweeney C, Herrick J, Wolff RK, Albertsen $\mathrm{H}$. APC mutations and other genetic and epigenetic changes in colon cancer. Mol Cancer Res 2007; 5: 165-70.

21. Flecher $\mathrm{RH}$. Colorectal cancer screening on stronger footning. N Engl J Med 2008; 359: 1285-7.

22. Gilinsky NH, Urlich CD. Colonic Tumores. Endoscopy 1996; 28: 83106.

23. Waye JD. Polyps large and small. Gastrointest Endosc 1992; 38: 391-6.

24. Ladabaum U, Song K. Projected naarional impaact of colorectal kancer screening on clinical and economic outcomes and healh sevices demands. Gatroenterology 2005; 129: 1151-62.

25. Makinen MJ, George SM, Jernvall P, Makela J, Vihko P, Karttunen TJ. Colorectal carcinoma associated with serrated adenoma - prevalence, histological features, and prognosis. J Pathol 2001; 193: 286-94.

\section{Address for correspondence}

\section{Dariusz Waniczek}

Chair and Department of General and Gastrointestinal Surgery

Medical University of Silesia

ul. Żeromskiego 7

41-902 Bytom

e-mail: dariusz_waniczek@interia.pl

Submitted: 18.02 .2012

Accepted: $\quad$ 10.05.2012 